\title{
Bone Framework Graft through an Intraoral Approach in a Patient with Columellar Scar Contracture
}

\author{
Myung-Good Kim¹, Ie Hyon Park ${ }^{2}$, \\ Chang Sik Pak², Baek-Kyu Kim², \\ Jae Hoon Jeong ${ }^{2}$ \\ ${ }^{1}$ Gangnam Ratio Plastic Surgery Clinic, \\ Busan; ${ }^{2}$ Department of Plastic and \\ Reconstructive Surgery, Seoul National \\ University Bundang Hospital, Seoul \\ National University College of Medicine, \\ Seongnam, Korea
}

No potential conflict of interest relevant to this article was reported.
We present our experience with calvarial bone framework insertion through an intraoral approach for a patient who was at risk for columellar necrosis due to a previous open rhinoplasty. A 58-year-old woman exhibited severe columellar contracture, so that the columellar tissue was too fragile to be touched. We could not incise the columella and insert a new nasal implant through the bilateral rim incision. Moreover, the patient had septal cartilage perforation and collapse. The patient needed columellar support as well as nasal dorsum reconstruction. The authors decided to graft an autogenous L-strut bone framework through an intraoral approach. Two pieces of $5-\mathrm{cm} \times$ $1-\mathrm{cm}$ sized split calvarial bone were harvested and trimmed to fit the width and length of the nasal dorsum and columella. The right-angle-shaped bone framework was made with an absorbable plate and screws. Through a gingivobuccal incision, the bone framework graft was inserted and the graft was fixed with absorbable screws. The patient did not experience complications such as skin necrosis or inflammation. A bone framework grafted through an intraoral approach can be a good choice for patients who have experienced scar contracture in the columella, septal cartilage perforation, and collapse.

Keywords Contracture, Oral surgical procedures, Rhinoplasty

\section{INTRODUCTION}

There are a number of types of rhinoplasty techniques. It is clear that the open rhinoplasty approach has advantages in treating complex and difficult nasal deformities, because it allows a great range of nasal structures to be directly viewed. However, a transcolumellar incision may be troublesome [1]. The closed approach appears to be especially useful for simple nasal surgery. The surgeon's experience and sense of aesthetics are essential for the closed approach, because the operation is performed without exposing the nasal

Received: Jul 23, 2016 Revised: Sep 26, 2016 Accepted: Sep 27, 2016 Correspondence: Jae Hoon Jeong Department of Plastic and Reconstructive Surgery, Seoul National University Bundang Hospital, Seoul National University College of Medicine, 82, Gumi-ro 173 Beon-gil, Bundang-gu, Seongnam 13620, Korea. E-mail: drj2h@hanmail.net

Copyright @ 2016 The Korean Society for Aesthetic Plastic Surgery.

This is an Open Access article distributed under the terms of the Creative Commons Attribution Non-Commercial License (http://creativecommons.org/licenses/by-nc/4.0/) which permits unrestricted non-commercial use, distribution, and reproduction in any medium, provided the original work is properly cited. $\quad w w w . e-a a p s . o r g$ structures [2]. An intraoral approach can be used by anyone who wishes to avoid a nasal scar. Through an intraoral approach, surgeons can insert grafts or implants easily [3]. Surgeons must choose the appropriate approach that provides patients with the best aesthetic results.

We present our experience with calvarial bone framework insertion through an intraoral approach in a patient who had columellar scar contracture after open rhinoplasty.

\section{CASE REPORT}

A 58-year-old woman who had undergone rhinoplasty visited our hospital. The augmentation rhinoplasty had been carried out using Goretex $^{\circledR}$ (W.L. Gore \& Associates Inc., Flagstaff, AZ, USA) through the open rhinoplasty approach. The premaxillary area was also augmented using Goretex ${ }^{\circledR}$ through an intraoral approach. After several years, the implants had become distorted and displaced, causing pain and tenderness. The patient showed severe columellar scar contracture accompanied with an over-elevated nasal dorsum, short nose deformity, and turned-up nose. 


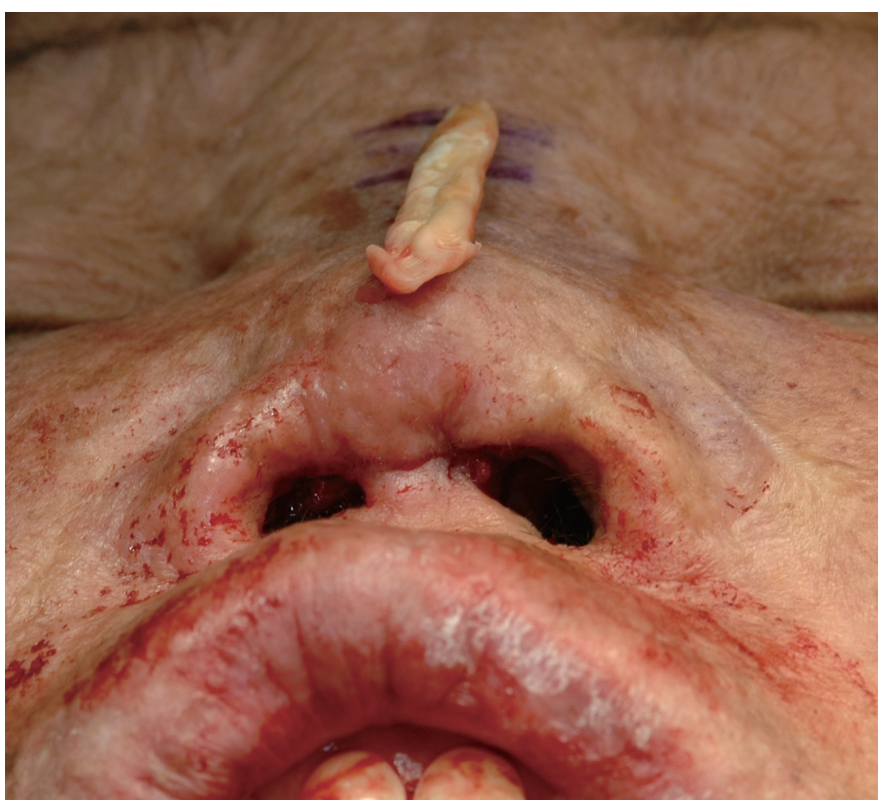

Fig. 1. Intraoperative photograph after the removal of previously inserted Goretex ${ }^{\circledR}$. The columellar scar was contracted and the implant was distorted and displaced.

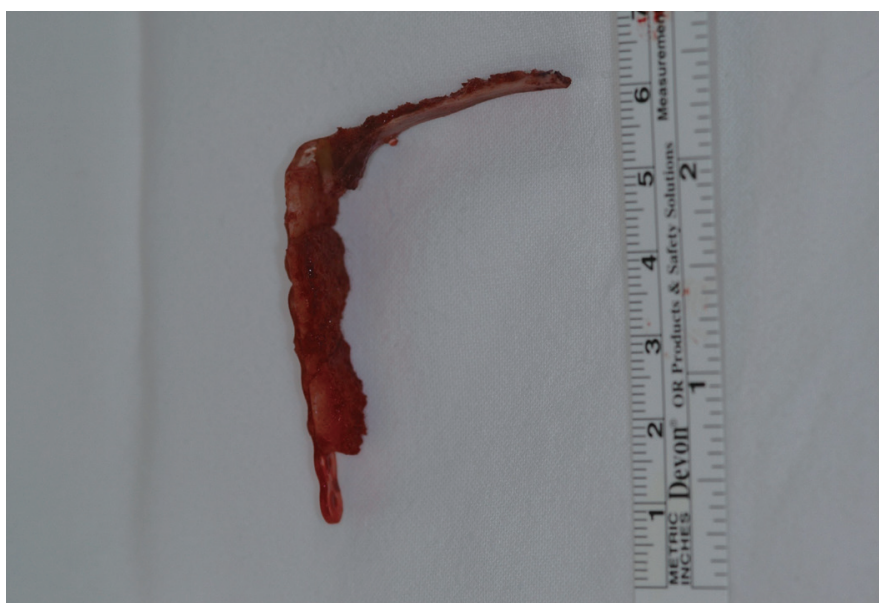

Fig. 2. Bone framework. The calvarial bone was harvested and fixed with absorbable plates and screws.

The patient wanted to remove the Goretex ${ }^{\circledR}$ on the nasal dorsum and premaxillary area due to the discomfort. At the same time, she did not want to worsen her appearance. With the patient's consent, the nasal implant was removed after bilateral rim incision, and the implant in the premaxillary area was removed through a gingivobuccal incision under general anesthesia (Fig. 1). However, severe columellar scar contracture was present and the surrounding tissue was fragile. The columellar tissue was too vulnerable to be touched. We were not able to incise the columella or insert new nasal implants through bilateral rim incisions. Moreover, the patient had septal cartilage perforation and collapse. The patient required colu-

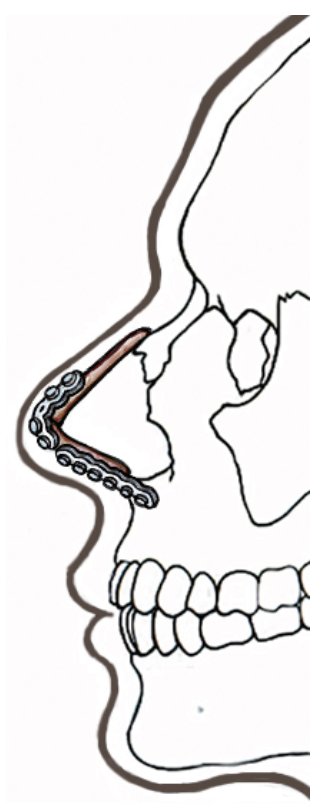

Fig. 3. Schematic design of the bone framework in situ. The caudal part of the bone framework was fixed at the anterior nasal spine of the maxilla.

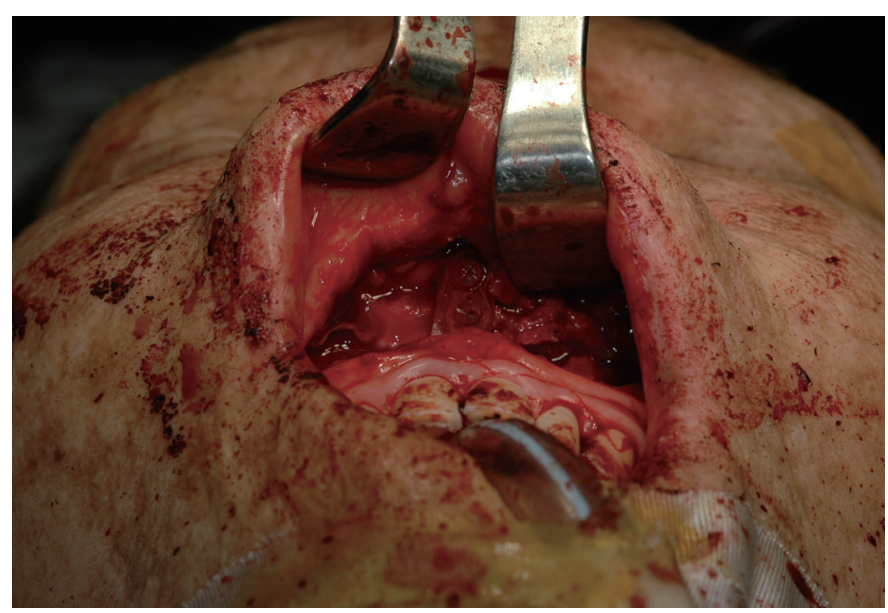

Fig. 4. Bone framework fixation. After the bone framework graft was inserted, the graft was fixed with an absorbable plate and screws.

mellar support as well as nasal dorsum reconstruction. We performed an autogenous L-strut bone framework graft through an intraoral approach. Two pieces of $5 \mathrm{~cm} \times 1 \mathrm{~cm}$ split calvarial bone were harvested and trimmed to fit the width and length of the nasal dorsum and columella. The right-angle-shaped bone framework was formed with an absorbable plates and screws (Fig. 2). Through a gingivobuccal incision, the tissue was spread open widely. After the bone framework graft insertion, the caudal part of the bone framework was fixed at the anterior nasal spine of the maxilla using an absorbable plate and screws (Fig. 3). We confirmed that it was solidly fixed (Fig. 4). The wound was closed without any problems. 

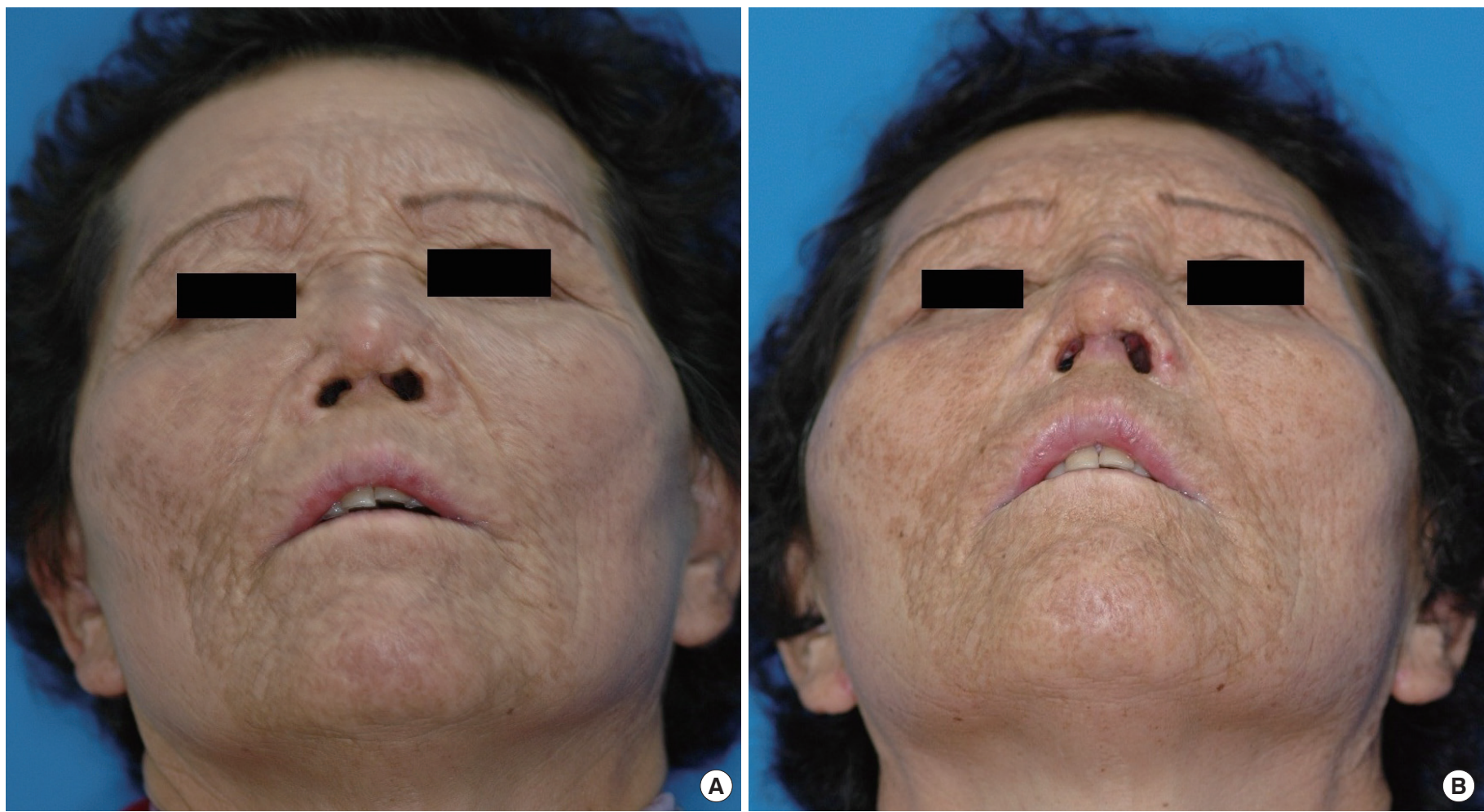

Fig. 5. Preoperative and postoperative worm's eye view photographs. The photographs were taken before (A) and 8 months after the operation (B). The columella was longer after the operation.
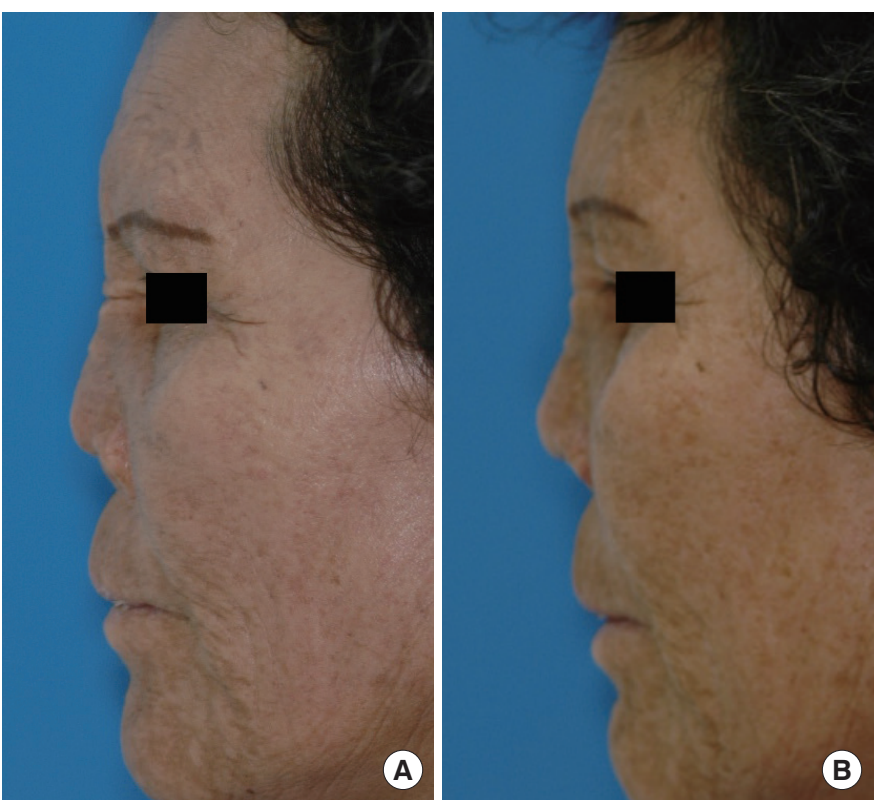

Fig. 6. Preoperative and postoperative lateral view photographs. The photographs were taken before (A) and 8 months after the operation (B). Nasal tip projection was well maintained and the nasal dorsum was slightly lowered, at the patient's request.

The patient did not experience any complications, such as columellar necrosis or graft inflammation. A photograph taken 8 months after the operation shows a lengthened columella and good nasal tip projection (Fig. 5 and 6 ). The patient was satisfied with the outcome.

\section{DISCUSSION}

Multiple autogenous and alloplastic implants are used for augmentation rhinoplasty and the reconstruction of nasal deformities. Autogenous implants include auricular and septal cartilage grafts as well as rib bone and iliac crest bone grafts. Alloplastic materials include acrylic, supramid mesh, Goretex ${ }^{\circledR}$, and silicone rubber. Autogenous grafts have been shown to provide excellent, long-term, reliable results in nasal reconstruction [4]. Autologous and homologous cartilages have proven to be more efficient in the correction of minor deficiencies of the columella, nasal dorsum, and nasal tip. However, these are inadequate for major bony defects that require structural reconstruction due to the limited size of the cartilage, unpredictable resorption rates, and their inability to achieve fixation to the underlying bone [5].

Autogenous calvarial grafts were used in the 1890s as part of an osteocutaneous flap by König and Müller. In 1983, Jackson et al. [6] reported their experience with autogenous calvarial grafts in nasal reconstruction. Calvarial grafts can be harvested easily. Moreover, the scar is often unnoticeable because it is covered with hair. The donor site is not painful compared with other bone graft donor 
sites. In addition, recent studies have indicated that calvarial bone grafts have better survival rates than nonmembranous bone grafts obtained from other donor sites [7]. The risk of intracranial injury during harvesting has been mentioned, but clinical reports are rare.

Recent studies have addressed the importance of rigid fixation for primary bone healing with decreased absorption. When onlayed autogenous bone grafts are rigidly fixed, improved results can be expected with respect to graft resorption, regardless of the type of bone utilized (membranous versus endochondral). The experimentally proven advantages of rigid fixation include primary bone healing and reduced bone resorption [8]. Other studies have shown that craniofacial bone healing using absorbable fixation systems offers results similar to those of metallic fixation systems, with lower rates of complications [9]. Once grafts became adherent enough to the recipient site to resist external mechanical forces, the type of fixation employed makes no difference. In our surgery, the surface of the bone framework was not completely in contact with the normal periosteum and bone. Therefore, a higher resorption rate is expected than has been observed in recent research. Nevertheless, we used a bone framework because it provides a strong supporting force and will act as a scaffold for a certain time.

In this case, we chose an intraoral approach because the patient had severe scar contracture of the columella and the adjacent tissues were too vulnerable to make a transcolumellar incision. Through the intraoral incision, we were not only able to sufficiently expose the previously grafted material, but were also able to prevent further scar contracture of the columella and easily fix the bony framework to the anterior nasal spine. However, the depressor septi nasi muscle could be damaged when using an intraoral approach. During the short-nose correction, the contracted soft tissue had to be sufficiently released and the autologous grafts had to provide mechanical support to prevent relapse. Furthermore, over-dissection of nasal soft tissue could result in contracture that would worsen the short-nose deformity.

To our knowledge, nasal grafting using an intraoral approach in patients with columellar scar contracture has rarely been reported.
Our experience is meaningful because this patient underwent nasal grafting with a calvarial bone framework, using an absorbable plate and screws through an intraoral approach.

We confirmed the realistic possibility and good aesthetic results of bone framework grafting through an intraoral approach in a patient who had scar contractures in the columella, septal cartilage perforation, and collapse.

\section{PATIENT CONSENT}

Patients provided written consent for the use of their images.

\section{REFERENCES}

1. Sevin A, Sevin K, Erdogan B, et al. Open rhinoplasty without transcolumellar incision. Ann Plast Surg 2006;57:252-4.

2. Bruschi S, Bocchiotti MA, Verga M, et al. Closed rhinoplasty with marginal incision: our experience and results. Aesthetic Plast Surg 2006; 30:155-8.

3. Webster RC, Hopping SB, Hall B, et al. Intraoral insertion of grafts to project the nasal tip. Arch Otolaryngol 1982;108:187-93.

4. Romo T, 3rd, Jablonski RD. Nasal reconstruction using split calvarial grafts. Otolaryngol Head Neck Surg 1992;107:622-30.

5. Wheeler ES, Kawamoto HK, Zarem HA. Bone grafts for nasal reconstruction. Plast Reconstr Surg 1982;69:9-18.

6. Jackson IT, Smith J, Mixter RC. Nasal bone grafting using split skull grafts. Ann Plast Surg 1983;11:533-40.

7. Jackson IT, Choi HY, Clay R, et al. Long-term follow-up of cranial bone graft in dorsal nasal augmentation. Plast Reconstr Surg 1998;102:186973.

8. Posnick JC, Seagle MB, Armstrong D. Nasal reconstruction with fullthickness cranial bone grafts and rigid internal skeleton fixation through a coronal incision. Plast Reconstr Surg 1990;86:894-902.

9. Eppley BL, Sadove AM. A comparison of resorbable and metallic fixation in healing of calvarial bone grafts. Plast Reconstr Surg 1995;96: 316-22. 